\author{
ДОВЕРИЕ К ВЛАСТИ \\ В РЕСПУБЛИКЕ АДЫГЕЕ \\ И КРАСНОДАРСКОМ КРАЕ \\ (ПО РЕЗУЛЬТАТАМ \\ ПРИКЛАДНОГО \\ ИССЛЕДОВАНИЯ) ${ }^{1}$
}

\begin{abstract}
(C) 2021 г.
3. A. Жаде *

* Адыгейский государственный университет, 2. Майкоп, Россия
\end{abstract}

Цель исследования заключается в определении уровня доверия граждан к властным институтам в условиях COVID-кризиса в Республике Адыгее и Краснодарском крае.

Методологическую базу исследования составили: междисциплинарный подход к измерению доверия к власти; принцип системности позволил рассмотреть взаимодействие власти и общества в контексте структурно-функциональных изменений данной системы; метод опроса позволил замерить уровень доверия к власти и оценить воздействие пандемии, разработать механизмы укрепления доверия к органам власти с учетом региональной специфики; метод анализа вторичной социологической информации позволил скоррелировать данные, полученные в ходе эмпирического исследования; сравнительный метод позволил сопоставить уровень доверия к власти в двух регионах, а также проанализировать особенности проявления доверия квласти в исследуемых регионах, исходя из различий в их политико-правовом статусе (национальная республика и край).

\section{TRUST TO THE AUTHORITIES IN THE REPUBLIC OF ADYGEA AND KRASNODAR TERRITORY (BASED ON THE RESULTS OF APPLIED RESEARCH)}

\author{
(C) 2021 \\ Z. A. Zhade * \\ * Adyghe State University, \\ Maykop, Russia
}

Objective of the study is determine the level of citizens' trust in government institutions in the conditions of the COVID crisis in the Republic of Adygea and the Krasnodar Territory.

The methodological basis of the research consists of an interdisciplinary approach to measuring trust in authority; the principle of consistency made it possible to consider the interaction of authority and society in the context of structural and functional changes in this system; the survey method made it possible to measure the level of trust in the authorities and assess the impact of the pandemic, to develop mechanisms to strengthen trust in the authorities, taking into account the regional specifics; the method of analysis of secondary sociological information allowed to correlate the data obtained in the course of empirical research; the comparative method made it possible to compare the level of trust in the authorities in the two regions, as well as to analyze the features of the manifestation of trust in the authorities in the studied regions, based on the differences in their political and legal status (national republic and territory).

${ }^{1}$ Исследование выполнено при финансовой поддержке РФФИ и ЭИСИ в рамках научного проекта № 21-011-31778. 
Результаты исследования. Данные социологического исследования подтверждают довольно низкий уровень доверия граждан к региональным институтам власти. На основе оценок населения двух регионов к основным факторам, от которых зависит уровень доверия к власти, относятся: во-первых, усиление персональной ответственности руководителей органов власти; во-вторых, открытость и прозрачность деятельности органов власти; в-третьих, учет общественного мнения при принятии решений.

Перспективы исследования. Результаты исследования могут быть использованы при расчете индекса доверия и анализе его основных компонентов и характеристик на региональном уровне; определении информационно-коммуникативных, организационных, правовых и иных технологий повышения доверия населения к власти, в том числе в пространстве социальных медиа; выявлении эффективных механизмов укрепления институционального доверия; определении путей повышения эффективности управленческих технологий с целью укрепления доверия населения к органам региональной власти.

Ключевые слова: доверие; власть; институциональное доверие; эффективность власти; ковид-кризис; регион
Research results. Sociological research data confirm a rather low level of citizens' trust in regional institutions of power. Based on the assessments of the population of the two regions, the main factors on which the level of trust in the authorities depends are: first, the strengthening of the personal responsibility of the heads of the authorities; secondly, the openness and transparency of the activities of the authorities; third, it is necessary to take public opinion into account when making decisions.

Prospects of the study. The research results can be used to calculate the trust index and analyze its main components and characteristics at the regional level; determination of information and communication, organizational, legal and other technologies for increasing public trust in the authorities, including in the space of social media; identification of effective mechanisms for strengthening institutional trust; revealing ways to improve the efficiency of management technologies in order to strengthen public trust in regional authorities.

Keywords: trust; power; institutional trust; effectiveness of authorities; COVID-crisis; region

\section{Введение}

Доверие наделяет власть значимыми ресурсами, которые необходимы для принятия и практической реализации различных государственных решений. Оно также характеризуется включенностью в механизм легитимации, влияет на формирование социальной опоры существующего режима, функционирующих государственных институтов и реализуемой ими социальной и экономической политики. В более широком смысле доверие предстает в качестве одного из основополагающих факторов, обеспечивающих устойчивость общества, его эффективное поступательное развитие и социальную интеграцию.

Продолжающийся ковид-кризис определяет актуальность поиска технологий и механизмов укрепления доверия россиян к власти. «В сложившихся условиях повышенных социальных рисков, связанных с 
негативными правовыми, духовными и морально-этическими последствиями перехода в новый цифровой технологический уклад, актуализация проблемы доверия населения к власти вызвана растущим разрывом между социально-экономическими и политическими ожиданиями людей и выполнением властью своих обещаний. В этих обстоятельствах доверие к проводимой государством политике становится ключевым фактором, способным придать гражданам уверенность в будущем, повысить их личную ответственность и эффективность их деятельности» (Ильичева, 2021. С. 163).

Актуальность поставленной проблемы подтверждается еще и тем, что в новой ст. 75 Конституции Российской Федерации доверие закреплено в качестве одного из приоритетов: «В Российской Федерации создаются условия для устойчивого экономического роста страны и повышения благосостояния граждан, для взаимного доверия государства и общества, гарантируются защита достоинства граждан и уважение человека труда, обеспечиваются сбалансированность прав и обязанностей гражданина, социальное партнерство, экономическая, политическая и социальная солидарность» ${ }^{2}$. Более того, в указе Президента РФ, подписанном 4 февраля 2021 г., доверие обозначено главным критерием эффективности власти ${ }^{2}$.

Изучение доверия к власти показывает сложную природу данного феномена. В настоящее время значительно возрос исследовательский интерес к доверию к власти - предмету изучения различных отраслей социогуманитарной науки, в рамках которой можно выделить такие основные подходы, как концептуализация доверия в теории риска, доверие как элемент социального капитала и доверие в культурологическом аспекте.

Следует согласиться с коллегами в том, что «категориальная диалектическая пара “доверие/недоверие” является чрезвычайно сложным, комплексным понятием, обладающим весьма высоким содержательным научным потенциалом, для которого, по крайней мере, на данный момент времени, теоретическое понимание является еще достаточно ограниченным» (Сасаки, 2013. С. 60-61). В этой связи в данной статье обратимся к рассмотрению уровня доверительных отношений граждан к институтам власти двух российских регионов.

\footnotetext{
${ }^{1}$ Конституция Российской Федерации. [Электронный ресурс]. URL: http:// www.consultant.ru/ document/cons_doc_LAW_28399/.

2 Указ Президента Российской Федерации от 4 февраля 2021 года № 68 «Об оценке эффективности деятельности высших должностных лиц (руководителей высших исполнительных органов государственной власти) субъектов Российской Федерации и деятельности органов исполнительной власти субъектов Российской Федерации». [Электронный ресурс]. URL: https://www.garant.ru/products/ipo/prime/doc/400181504/.
} 


\section{Концепция и эмпирическая база исследования}

Механизмы укрепления доверия к власти в пандемийный период недостаточно изучены, вместе с тем российские ученые активно обсуждают векторы развития гражданского общества и государства в условиях ковид-кризиса (Общество и пандемия ..., 2020; Пандемия COVID-19 .., 2021; «Черный лебедь» ..., 2021).

Концептуальные рамки настоящего исследования определяются также идеями, согласно которым политическое доверие - это «уверенность граждан страны (или некоторой их части) в правильности политических позиций и действий тех или иных политических сил, институтов, государственных и политических деятелей, соответствии их политических позиций своим собственным убеждениям, в способности конкретных политических субъектов реализовать провозглашенные цели и программные установки, готовность оказывать им поддержку» (Козырева, 2015. С. 81).

В проведенном нами исследовании доверие к власти рассматривается как своеобразная форма отношения к отдельным властным институтам и их представителям со стороны населения, выражающаяся в оценках их деятельности.

С целью определения степени доверия населения к органам власти в условиях ковид-кризиса исследовательским коллективом Адыгейского государственного университета в сентябре-октябре 2021 г. проведен социологический опрос в Республике Адыгее (РА) и Краснодарском крае (КК). Основным инструментарием является стандартизированная анкета, пригодная для личного анкетирования и применяемая в Google Forms с анонимным заполнением респондентами. Опрос проведен по квотно-пропорциональной выборке. Основные вопросы анкеты представлены с целью сравнительного анализа с результатами предыдущего аналогичного исследования (Жаде, 2020). В качестве эмпирического объекта выступило население четырех муниципальных образований республики и края (город Майкоп, Красногвардейский, Тахтамукайский и Теучежский районы $(\mathrm{N}=508)$ и город Краснодар, Белореченский, Курганинский и Лабинский районы $(\mathrm{N}=583))$.

\section{Результаты исследования}

Одним из главных показателей доверия властным структурам является степень личностного доверия граждан. За отправную точку анализа приняты результаты исследования, в основе которых лежат 
ответы респондентов на вопрос «Доверяете ли Вы следующим органам, структурам, институтам в условиях пандемии?». Данные исследования показывают, что главе республики и губернатору края 27,1 и $20 \%$ респондентов полностью доверяют, скорее доверяют 32 и $27,9 \%$, скорее не доверяют 12,4 и 19,3\%, не доверяют 7,4 и $15 \%$, затруднились ответить 20,8 и 17,4 \% (табл. 1 ).

Таблица 1

\section{Распределение ответов на вопрос «Доверяете ли Вы следующим органам, структурам, институтам в условиях пандемии?», \%}

(один вариант ответа)

\begin{tabular}{|l|c|c|c|c|c|c|c|c|c|c|}
\hline \multirow{2}{*}{ Вариант ответа } & \multicolumn{2}{|c|}{$\begin{array}{l}\text { Полностью } \\
\text { доверяю }\end{array}$} & \multicolumn{2}{c|}{$\begin{array}{c}\text { Скорее } \\
\text { доверяю }\end{array}$} & \multicolumn{2}{c|}{$\begin{array}{c}\text { Скорее не } \\
\text { доверяю }\end{array}$} & \multicolumn{2}{c|}{$\begin{array}{c}\text { Не } \\
\text { доверяю }\end{array}$} & \multicolumn{2}{|c|}{$\begin{array}{c}\text { Затрудняюсь } \\
\text { ответить }\end{array}$} \\
\cline { 2 - 14 } & РА & КК & РА & КК & РА & КК & РА & КК & РА & КК \\
\hline Президенту РФ & 25,9 & 29,1 & 27,9 & 25,3 & 16 & 13,8 & 9,6 & 13,3 & 20,8 & 18,1 \\
\hline Главе региона & 27,1 & 20 & 32 & 27,9 & 12,4 & 19,3 & 7,4 & 15 & 20,8 & 17,4 \\
\hline $\begin{array}{l}\text { Исполнительным ор- } \\
\text { ганам власти региона }\end{array}$ & 20,4 & 19 & 27,6 & 27 & 18,3 & 20 & 8,6 & 15 & 20,8 & 17,6 \\
\hline $\begin{array}{l}\text { Законодательным ор- } \\
\text { ганам власти региона }\end{array}$ & 19,4 & 18,5 & 27,6 & 27,6 & 18,7 & 20 & 8,8 & 15 & 21,2 & 17,4 \\
\hline $\begin{array}{l}\text { Администрации } \\
\text { города/села }\end{array}$ & 19 & 19 & 33 & 28,3 & 17,7 & 19,3 & 8,4 & 15,6 & 21,6 & 17,6 \\
\hline $\begin{array}{l}\text { Правоохранительным } \\
\text { органам }\end{array}$ & 21 & 19,3 & 33,2 & 28,8 & 15,7 & 20,4 & 8,8 & 14,5 & 21 & 16,8 \\
\hline $\begin{array}{l}\text { Организациям } \\
\text { здравоохранения }\end{array}$ & 20,4 & 19,2 & 33 & 32 & 16,1 & 17,8 & 10,6 & 14,9 & 19,6 & 15,9 \\
\hline $\begin{array}{l}\text { Общественным } \\
\text { организациям }\end{array}$ & 18,3 & 17,8 & 34,2 & 33,1 & 16,5 & 17,1 & 8,8 & 13,5 & 22 & 18,3 \\
\hline СМИ & 15,3 & 16,1 & 31,1 & 27,7 & 21 & 18,3 & 11 & 19,8 & 21,4 & 17,8 \\
\hline
\end{tabular}

Уровень доверительного отношения граждан к президенту РФ в обоих регионах практически аналогичен: 27,1 и 29,1 \% полностью доверяют; 27,9 и 25,3 \% скорее доверяют; 16 и 13,8 \% скорее не доверяют. И только 9,6 и 13,3 \% не доверяют (табл. 1). Как нам представляется, эти данные являются свидетельством того, что российский глава в глазах граждан выступает символом стабильности и порядка в стране.

Согласно полученным результатам, среди институтов власти наибольшим доверием у населения пользуются правоохранительные органы (21 и 19,3 \%), чуть меньше доверия вызывали у респондентов исполнительные $(20,4$ и 19 \%) и законодательные органы власти $(19,4$ и $18,5 \%)$. На одном уровне (19\%) в двух регионах оценены администрации города/села. В наименьшей степени население доверяет обществен- 
ным организациям (18,3 и 17,8 \%) и средствам массовой информации (15,3 и 16,1\%) (табл. 1).

В рамках исследования предпринята попытка выяснить главные причины недоверия к власти. В целом неэффективность принимаемых региональными органами власти решений и мер названа населением в качестве основной причины недоверия к власти $(24,6$ и 25,6 \%). В числе других причин граждане назвали злоупотребление властью (22 и 23 \%), а также 20,7 и 16,1 \% опрошенных видят причину в некомпетентности, низком уровне профессионализма соответствующих органов власти в случае обращения граждан для решения какой-либо проблемы. 19,1 и 21,8 \% называют закрытость власти, недостаточное информирование населения о ситуации в регионе и проводимых мерах; 9,4 и 9,8 \% указали на низкий нравственный уровень власти (табл. 2).

Таблий 2

Распределение ответов на вопрос «Каковы могут быть главные причины недоверия к власти?», \%

(несколько вариантов ответа)

\begin{tabular}{|l|c|c|}
\hline \multicolumn{1}{|c|}{ Вариант ответа } & РА & КК \\
\hline Неэффективность принимаемых решений и мер & 24,6 & 25,6 \\
\hline Злоупотребление властью & 22 & 23 \\
\hline $\begin{array}{l}\text { Некомпетентность, низкий уровень профессионализма со- } \\
\text { ответствующих органов власти в случае обращения граж- } \\
\text { дан для решения какой-либо проблемы }\end{array}$ & 20,7 & 16,1 \\
\hline $\begin{array}{l}\text { Закрытость власти, недостаточное информирование населе- } \\
\text { ния о ситуации в регионе и проводимых мерах }\end{array}$ & 19,1 & 21,8 \\
\hline Низкий нравственный уровень власти & 9,4 & 9,8 \\
\hline
\end{tabular}

Доверие к власти во многом определяется степенью ее открытости перед обществом. Это подтверждает распределение ответов на вопрос о мерах повышения доверия к органам власти. В обеих группах подавляющее большинство выбрали вариант «открытость и прозрачность деятельности органов власти» (44,7 и 44,4 \%). Доли тех, кто указал на вариант «усиление персональной ответственности руководителей органов власти», также практически не различаются $(39,8$ и 37,4 \%). Одним из механизмов повышения доверия к представителям власти является учет общественного мнения. Этот вариант выбрали 38,4 и 41,5 \% респондентов (табл. 3). 
Таблица 3

Распределение ответов на вопрос «Какие меры могут влиять на повышение доверия к органам власти?», \%

\begin{tabular}{|c|c|c|}
\hline Вариант ответа & PA & KК \\
\hline $\begin{array}{l}\text { Усиление персональной ответственности руководителей } \\
\text { органов власти }\end{array}$ & 39,8 & 37,4 \\
\hline Открытость и прозрачность деятельности органов власти & 44,7 & 44,4 \\
\hline Учет общественного мнения при принятии решений & 38,4 & 41,5 \\
\hline Равноправный диалог власти и общества & 30,9 & 35 \\
\hline $\begin{array}{l}\text { Возможность реального участия граждан в процессе } \\
\text { управления }\end{array}$ & 19,7 & 24 \\
\hline Принимаемые решения должны быть справедливыми & 31,3 & 29,7 \\
\hline Усиление общественного контроля & 13 & 15,6 \\
\hline $\begin{array}{l}\text { Повышение качества предоставления государственных } \\
\text { услуг }\end{array}$ & 28,1 & 29 \\
\hline Решение проблем конкретных людей на местах & 17,9 & 24,5 \\
\hline Затрудняюсь ответить & 10,8 & 8,4 \\
\hline
\end{tabular}

Доверие к власти имеет непосредственную взаимосвязь как с базовыми, так и с ситуационными представлениями о власти, которые отражаются в знаниях и представлениях о ней, а также в соответствующих ценностях и ориентациях. Индивидам свойственно соотносить действия, осуществляемые органами государственной власти, с собственными ценностями и ожиданиями от нее. На этой основе может происходить формирование идентификации с властью как своей, близкой или, напротив, чужой и враждебной. Иными словами, предпосылкой формирования высокого уровня доверия к власти является соответствие ценностных ориентаций граждан и их ожиданий от власти ее реальной деятельности, содержанию проводимой государственной политики.

В рамках проведенного исследования нас интересовала точка зрения респондентов касательно основных слагаемых доверия к власти. По мнению респондентов, большое значение для повышения доверия к органам власти имеет в первую очередь вера в честность и порядочность представителей власти (28,7 и 30,5\%); во-вторых, уверенность в надлежащем исполнении властью своих функций (28,5 и 30 \%); в-третьих, активная поддержка органов власти $(24,4$ и 19,2 \%). Опрошенные граждане полагают, что в этом процессе вообще не имеет значения привычка доверять власти, традиции (17,3 и 25,4 \%) (табл. 4). 


\section{Распределение ответов на вопрос «Из чего складывается доверие к власти?», \%}

Таблий 4

(один вариант ответа)

\begin{tabular}{|l|c|c|c|c|}
\hline \multicolumn{1}{|c|}{ Вариант ответа } & \multicolumn{2}{|c|}{$\begin{array}{c}\text { Вообще } \\
\text { не имеет } \\
\text { значения }\end{array}$} & \multicolumn{2}{|c|}{$\begin{array}{c}\text { Имеет } \\
\text { большое } \\
\text { значение }\end{array}$} \\
\cline { 2 - 6 } & РА & КК & РА & КК \\
\hline $\begin{array}{l}\text { Поддержка действий и мер, реализуемых } \\
\text { властью }\end{array}$ & 13,6 & 14,4 & 23 & 23,3 \\
\hline Согласие с проводимой политикой власти & 13,2 & 15,1 & 19,7 & 20,1 \\
\hline $\begin{array}{l}\text { Справедливость принимаемых властью ре- } \\
\text { шений }\end{array}$ & 13,6 & 13,9 & 32,7 & 34,5 \\
\hline Привычка доверять власти, традиции & 17,3 & 25,4 & 20,3 & 12,5 \\
\hline $\begin{array}{l}\text { Уверенность в надлежащем исполнении } \\
\text { властью своих функцй }\end{array}$ & 13,6 & 14,5 & 28,5 & 30 \\
\hline $\begin{array}{l}\text { Вера в честность и порядочность предста- } \\
\text { вителей власти }\end{array}$ & 15,1 & 17 & 28,7 & 30,5 \\
\hline Активная поддержка органов власти & 15,7 & 17,8 & 24,4 & 19,2 \\
\hline
\end{tabular}

На наш взгляд, к мерам, предусмотренным для повышения уровня доверия к власти, в первую очередь необходимо отнести предоставление гражданам возможности воздействовать на процесс принятия управленческих решений. Респонденты обоих регионов, отвечая на вопрос о возможности граждан оказывать влияние на решения органов власти, чаще склоняются к мнению, что практически не имеют $(35,2$ и 41,7 \%). Ответ «в отдельных случаях» выбрали 30,5 и 28,5 \%. Только 13,2 и 12,9 \% убеждены в том, что граждане могут влиять на управленческие решения. И в этом вопросе мнение опрошенного населения рассматриваемых регионов в целом совпадает.

\section{Заключение}

Анализ уровня доверия, причин недоверия, слагаемых доверия, мер по повышению доверия к власти, основанный на результатах прикладного исследования, позволяет сделать вывод о том, что население двух обозначенных регионов в целом аналогично высказывает свои позиции. Основная причина этого, на наш взгляд, заключается в том, что республика и край имеют одинаковый статус субъекта Федерации и относятся к ЮФУ. 
Данные социологического исследования подтверждают довольно низкий уровень доверия граждан к региональным институтам власти. На основе оценок населения Республики Адыгеи и Краснодарского края выделены основные факторы, от которых зависит уровень доверия к власти: во-первых, усиление персональной ответственности руководителей органов власти; во-вторых, открытость и прозрачность деятельности органов власти; в-третьих, учет общественного мнения при принятии решений.

В настоящее время научный коллектив Адыгейского государственного университета занимается исследованием механизмов укрепления повышения доверия населения к власти в условиях ковид-кризиса (на примере Республики Адыгеи и Краснодарского края), презентация которого будет представлена в следующих публикациях.

\section{Литература}

Жаде 3.А., Шадже А.Ю., Ляушева С.А., Ильинова Н.А., Куква Е.С. Региональная власть и общество в условиях неопределенности и риска: индекс (дез)интеграции как основа модели взаимодействия // Вестник Адыгейского государственного университета. Серия «Регионоведение: философия, история, социология, юриспруденция, политология, культурология». 2020. Вып. 4. C. 104-121.

Ильичева Л.Е., Кондрашов А.О., Лапин A.B. Доверие как мост над пропастью неуверенности между властью и обществом // Мониторинг общественного мнения: экономические и социальные перемены. 2021. № 2. C. 162-185.

Козырева П.М., Смирнов А.И. Политическое доверие в России: некоторые особенности и проблема оптимальности // Вестник Института социологии. 2015. № 12. С. 79-99.

Общество и пандемия: опыт и уроки борьбы с COVID-19 в России / отв. ред. В.А. Мау, Я.И. Кузьминов, А.Д. Радыгин, В.А. Садовничий, С.Г. Синельников-Мурылев. М.: Аналитический центр при Правительстве Российской Федерации, 2020. 744 с.

Пандемия COVID-19: вызовы, последствия, противодействие / под ред. А.В. Торкунова, С.В. Рязанцева, В.К. Левашова. М.: Аспект Пресс, 2021. 248 с.

\section{References}

Zhade, Z.A., Shadzhe, A.Yu., Lyausheva, S.A., Il'inova, N.A., Kukva, E.S. (2020). Regional power and society in conditions of uncertainty and risk: the index of (dis) integration as the basis of the interaction model. Vestnik Adygeyskogo gosudarstvennogo universiteta. Seriya «Regionovedeniye: filosofiya, istoriya, sotsiologiya, yurisprudentsiya, politologiya, kul'turologiya», 4, 104-121. (In Russian).

Ilyicheva, L.E., Kondrashov, A.O., Lapin, A.V. (2021). Trust as a bridge over the chasm of uncertainty between the government and society. Monitoring obshchestvennogo mneniya: ekonomicheskiye $i$ sotsial'nyye peremeny, 2, 162-185. (In Russian).

Kozyreva, P.M., Smirnov, A.I. (2015). Political trust in Russia: some features and the problem of optimality. Vestnik Instituta sotsiologii, 12, 79-99. (In Russian).

Society and Pandemic: experience and lessons from COVID-19 fighting in Russia. (2020). V.A. Mau, Ya.I. Kuzminov, A.D. Radygin, V.A. Sadovnichy, S.G. Sinelnikov-Murylev (Resp. Eds.). Moscow: Analiticheskiy tsentr pri Pravitel'stve Rossiyskoy Federatsii Press. (In Russian).

Pandemic COVID-19: Challenges, consequences, counteraction. (2021). A.V. Torkunov, S.V. Ryazantsev, V.K. Levashov (Eds.). Moscow: Aspekt Press. (In Russian).

Sasaki, M., Davydenko, V.A., Romash- 
Сасаки М., Давыденко В.А., Ромашкина Г.Ф., Воронов В.В. Сравнительный анализ доверия в различных странах // Социс. 2013. № 3. С. 60-73.

«Черный лебедь» в белой маске : аналит. докл. НИУ ВШЭ к годовщине пандемии COVID-19 / под ред. С.М. Плаксина, А.Б. Жулина, С.А. Фаризовой. М.: Изд. дом Высшей школы экономики, 2021. $336 \mathrm{c.}$

Для цитирования: Жаде З.А. Доверие к власти в Республике Адыгее и Краснодарском крае (по результатам прикладного исследования) // Гуманитарий Юга России. 2021. 5 (51). C. 122-131.

DOI $10.18522 / 2227-8656.2021 .5 .8$

\section{Сведения об авторе}

\section{Жаде Зуриет Анзауровна}

Доктор политических наук, профессор, заведующая кафедрой теории и истории государства и права и политологии, Адыгейский государственный университет

385000, Республика Адыгея, г. Майкоп, ул. Первомайская, 208, e-mail: zhadezura@yandex.ru kina, G.F., Voronov, V.V. (2013). Comparative analysis of trust in different countries. Sotsis, 3 , 60-73. (In Russian).

«Black Swan» in a white mask. (2021). Analytical report of the Higher School of Economics on the anniversary of the COVID-19 pandemic. S.M. Plaksin, A.B. Zhulin, S.A. Farizova (Eds.). Moscow: Izd. dom Vysshey shkoly ekonomiki Publ. (In Russian).

\section{История статьи:} Поступила в редакцию - 03.09.2021 г. Получена в доработанном виде 20.10.2021 г. Одобрена - 01.11.2021 г.

\section{Information about author}

\section{Zuriet Anzaurovna Zhade}

Doctor of Political Sciences, Professor, Head of the Department of Theory and History of State and Law and Political Science, Adyghe State University

208 Pervomayskaya St., Maykop, Republic of Adygea, 385000, e-mail: zhadezura@yandex.ru 